RESEARCH ETHICS

\title{
Multicentre trials review process by research ethics committees in Spain: where do they stand before implementing the new European regulation?
}

\author{
R Dal-Ré, R Ortega, E Morejón
}

See end of article for authors' affiliations

Correspondence to: Dr R Dal-Ré, Medical Department

GlaxoSmithKline, Parque

Tecnológico de Madrid,

C/ Severo Ochoa, 2

28760 Tres Cantos,

Madrid, Spain;

rafael.dal-re@gsk.com

Received 1 December 2003

In revised form

5 March 2004

Accepted for publication

19 April 2004
Objectives: To review the performance of research ethics committees (RECs) in Spain in assessing multicentre clinical trial (MCT) drug protocols, and to evaluate if they would comply with the requirements of the new EU Directive to be implemented by May 2004.

Design and setting: Prospective study of applications of MCT submitted to RECs.

Main measurements: Protocol related features and evaluation process dynamics.

Results: 187 applications (24 protocols, 18 study drugs) to be performed in 114 centres, were reviewed by 62 RECs. RECs had a median number of 14 members, of which three were lay members. All applications were approved except four which were however approved by the other RECs involved. The median times from submission to approval and from submission to reception at the sponsor's offices were 48 and 62 days, respectively. In 55\% (101/183) of all applications approved, 41 RECs raised 307 queries, $40 \%$ of these were protocol related issues, and 38\% related to the patients' information sheets. RECs charging an evaluation fee in advance and applications with no queries raised were statistically significantly associated with shorter evaluation times. However, there is a gap of at least 1.5 weeks between the date of the meeting and the reception of the approval letter in the sponsor's office.

Conclusions: Evaluating MCT protocols by RECs is a time consuming process. Needing 1.5 weeks for communicating the decision taken by RECs to the sponsor suggests serious administrative shortcomings within most RECs. By significantly reducing the time for communication of their decisions, the majority of RECs would comply with the Directive requirement of a maximum 60 day period for the assessment of MCT.
$\mathrm{T}$ here has been an increasing amount of literature published in recent years about the role of research ethics committees (RECs) in the whole clinical research process, from their efficiency in reviewing protocols ${ }^{1-4}$ to their role in ensuring publication of study results. ${ }^{67}$ There are no doubts regarding the increasing workload with which RECs have been dealing in the last decade which is due, among other things, to the increasing number of multicentre clinical trials (MCTs) submitted for review. ${ }^{8}$ Furthermore, a number of reports have pointed out that because of this higher workload, some of the RECs' responsibilities such as monitoring ongoing research and training REC members and investigators are being poorly (or not at all) fulfilled..$^{4} 9$

In some EU countries the MCT protocol is reviewed by all RECs involved. This multiplication of effort is expensive, time consuming, and has resulted in too much variety in response among the RECs involved ${ }^{1-3}{ }^{10}$ In an attempt to solve this situation, the UK moved forward by establishing multicentre research ethics committees, with defined roles and responsibilities. ${ }^{11}{ }^{12}$ Although the British system has some limitations, ${ }^{13}$ it may be considered as a step forward in the search for a rapid process compared with the situation in other countries, such as Spain ${ }^{14}$ and Italy, ${ }^{15}$ in which MCT protocols are reviewed in depth by all RECs involved. Because the development of a new medicine is a very competitive enterprise, involving considerable economic effort and requiring completion of the development programme within the shortest possible time, the European Commission has tried to ensure that European countries are competitive enough, in terms of time and quality, to attract investments in clinical research. To this end, in April 2001 a Directive $^{16}$ was officially adopted aiming, among other things, to "simplify and harmonise the administrative provisions governing" clinical trials on medicinal products within the EU. If everything goes on schedule, in May 2004 all European Union (EU) countries will have in place the provisions included in this directive. ${ }^{16}$

This directive brings critical changes to European countries such as, for example, the approach on how to address the approval process of MCTs. The directive states that for MCTs, either national or international, each EU country should establish a procedure based on the opinion of a single REC. ${ }^{16}$ Furthermore, the whole process of reviewing the MCT protocol and communicating the REC's decision to the applicant and the competent authority should take no longer than 60 days. ${ }^{16}$ This will affect the REC role in countries such as Spain and Italy, but not in others like France, in which a single REC opinion has been in place since $1988 .{ }^{17}$ In Spain, all RECs involved in an MCT assess the protocol from both scientific and ethical standpoints, as well as the suitability of local facilities, the researcher, and the patient's information sheet (PIS). ${ }^{14}$ The approval letter (official form) of the first REC must be sent to the sponsor who must then submit this (with the MCT complete dossier) to the Spanish Medicines Agency (SMA) for approval. ${ }^{14}$ There are currently 133 RECs (local and regional) in Spain, ${ }^{18}$ whose composition, number of members $(\geqslant 7)$, and responsibilities are specified by the regulation. ${ }^{14}$

Abbreviations: $M C T$, multicentre clinical trial; PIS, patient information sheet; REC, research ethics committee; SMA, Spanish Medicines Agency. 
Table 4 Time (days) from submission to approval, approval to reception and from submission to reception of the research ethics committees' (RECs) evaluations. Results for full sample of approved applications $(n=183)$ and by characteristics of RECs

\begin{tabular}{|c|c|c|c|c|c|c|}
\hline & \multicolumn{2}{|l|}{ Submission to approval } & \multicolumn{2}{|l|}{ Approval to reception } & \multicolumn{2}{|l|}{ Submission to reception } \\
\hline & $\begin{array}{l}\text { Mean (SD), } \\
\text { median, range }\end{array}$ & $p$ Value & $\begin{array}{l}\text { Mean (SD), } \\
\text { median, range }\end{array}$ & $\mathrm{p}$ Value & $\begin{array}{l}\text { Mean (SD), } \\
\text { median, range }\end{array}$ & p Value \\
\hline $\begin{array}{l}\text { Full sample } \\
\text { ( } n=62 \text { RECs) } \\
\text { Evaluation fee }\end{array}$ & 55.7 (33.7), 48, 7-188 & NA & $16.9(22.2), 10,0-195$ & NA & $72.4(39.1), 62,14-236$ & NA \\
\hline $\begin{array}{l}\text { Yes } \\
n=40 \\
\text { No }\end{array}$ & $\begin{array}{l}50.4(30.8), 45,7-174 \\
69.1(37.1), 69,15-188\end{array}$ & 0.001 & $\begin{array}{l}16(18.7), 9,0-105 \\
19(25.5), 14,0-195\end{array}$ & NS & $\begin{array}{l}66.3(35), 60,14-186 \\
88.04(44.7), 81,29-236\end{array}$ & 0.002 \\
\hline $\begin{array}{l}\text { No of members } \\
\geqslant 14 \\
n=33 \\
<14 \\
n=29\end{array}$ & $\begin{array}{l}52(30.5), 47,7-150 \\
60.7(35.8), 52,14-174\end{array}$ & NS & $\begin{array}{l}17.7(19.3), 13,0-105 \\
15.4(26.7), 8,0-195\end{array}$ & NS & $\begin{array}{l}69.7(34.3), 62,14-182 \\
75.2(45.4), 60,18-236\end{array}$ & NS \\
\hline
\end{tabular}

vaccines, and one therapeutic vaccine (oncology area). The protocol design features included 22 controlled studies, 17 of which were double blind. Fourteen studies were placebo controlled (of which four were add-on therapy). Seven protocols were conducted under an IND (US Investigational New Drug application). The applications involved 234 departments $(201$ in hospitals and 33 in primary care centres) of 85 different hospitals and 29 different primary care centres across the country. Table 1 shows the main protocol related features (therapy areas and development phase of the experimental product) and hospitals in which the 24 MCT were to be performed.

The 187 applications were evaluated by 62 different RECs. All except four submissions were eventually approved. RECs were located in 33 cities, with $47 \%$ of RECs being located in two regions: Catalonia $(15,24 \%)$ and Madrid $(14,23 \%)$. RECs in the Catalonia and Madrid regions assessed 112 $(60 \%)$ of the total number of applications. There were 53 local and six regional RECs. In addition, there were three regional RECs, only devoted to review clinical research to be performed in primary care centres. Main characteristics of the RECs involved in this study are shown in table 2. All RECs were chaired by physicians ( $85 \%$ males), except one chaired by a pharmacist (male).

The median number of protocol pages was 72 (range 53112, mean 73.3), whereas for the complete dossier was 237 (range 102-677, mean 275.5). Communication facilities with the sponsor included email (29\%, 18 RECs) and fax (87\%, 54
RECs). The final decision regarding on the protocol taken by the RECs was, in all cases, communicated by letter, although $54(87 \%)$ sent the letter by fax before.

Queries raised by RECs and course of events are shown in figure 1. The median number of queries per protocol was 9.5 (range 2-48, mean 12.8). A median of $50 \%$ of the RECs evaluating each protocol made queries (range 13$100 \%$, mean $53 \%$ ). This percentage was $>70 \%$ in seven of the 24 protocols. In 14 of the 24 protocols, $\geqslant 50 \%$ RECs made queries. No relation of the clinical trial phase (II, III, or IV) with the frequency of queries raised was observed. The distribution of main query types is depicted in table 3.

As shown in table 4, the median times from submission to approval of the protocol and from submission to reception by the sponsor of the approval letter were 48 and 62 days, respectively. The evaluation timings assessed by RECs' features such as whether they charge an evaluation fee or whether they have a number of members higher or lower than the median (14) are also shown in table 2. RECs that charged an evaluation fee showed statistically significantly shorter times for evaluation than those which did not charge a fee. Larger RECs, however, seemed to have no influence on the approval times. Times were also statistically significantly shorter for RECs not raising queries and for phase III trials (table 5). The six RECs assessing more MCT in Spain reviewed 54 (30\% of total) of the approved applications in our study, and evaluated a mean of nine

Table 5 Impact of queries raised by research ethics committees (RECs) and trial phase (II, III, or IV) on time (days) needed from submission to approval, approval to reception, and submission to reception of the REC's approval at the sponsor's office on the full sample of approved applications ( $n=183$ )

\begin{tabular}{|c|c|c|c|c|c|c|}
\hline & \multicolumn{2}{|l|}{ Submission to approval } & \multicolumn{2}{|l|}{ Approval to reception } & \multicolumn{2}{|l|}{ Submission to reception } \\
\hline & $\begin{array}{l}\text { Mean (SD), } \\
\text { median, range }\end{array}$ & p Value & $\begin{array}{l}\text { Mean (SD), } \\
\text { median, range }\end{array}$ & p Value & $\begin{array}{l}\text { Mean (SD), } \\
\text { median, range }\end{array}$ & p Value \\
\hline $\begin{array}{l}\text { Applications with queries } \\
\text { raised } n=101 \quad(N R=41)\end{array}$ & $63.5(37.6), 54.5,10-188$ & & $15.5(25.8), 8,0-195$ & & $79.1(45.1), 69,18-236$ & \\
\hline $\begin{array}{l}\text { Applications without } \\
\text { queries } n=82(N R=21) \\
\text { Trial phase }\end{array}$ & $47.1(26.3), 40.5,7-125$ & 0.003 & $18.4(17.6), 13.5,0-75$ & 0.022 & $65.2(30.1), 61,14-165$ & NS \\
\hline NAp $=54$ & $57.4(32.9), 49.5,14-150$ & & $15.7(15.5), 12.5,0-68$ & & $73.2(35.4), 61.5,18-169$ & \\
\hline III NAp $=78$ & $46.5(25.9), 41,7-125$ & $0.009^{*}$ & $16.2(26.2), 8,0-195$ & NS & $62.8(34.9), 56,14-236$ & $0.007^{*}$ \\
\hline$N A p=51$ & $67.9(40.8), 61.5,13-188$ & & $28.5(40.3), 28.5(0-57)$ & & $86.6(45.3), 83.5,24-188$ & \\
\hline
\end{tabular}

NR, number of RECs; NAp, number of applications submitted for each trial phase; NS, not significant.

${ }^{*} \mathrm{p}$ values marked for all between-phase comparisons. 
Table 6 Time (days) from submission to approval, approval to reception, and from submission to reception of the research ethics committees' (REC) evaluations. Comparison between the timings of the six RECs which evaluate the largest number of protocols per year in Spain (G6 RECs in the table) and the timings of the remaining $(n=56)$ RECs evaluating protocols in this study

\begin{tabular}{|c|c|c|c|c|c|c|}
\hline & \multicolumn{2}{|l|}{ Submission to approval } & \multicolumn{2}{|l|}{ Approval to reception } & \multicolumn{2}{|l|}{ Submission to reception } \\
\hline & $\begin{array}{l}\text { Mean (SD), } \\
\text { median, range }\end{array}$ & p Value & $\begin{array}{l}\text { Mean (SD), } \\
\text { median, range }\end{array}$ & p Value & $\begin{array}{l}\text { Mean (SD), } \\
\text { median, range }\end{array}$ & p Value \\
\hline $\begin{array}{c}\text { G6 RECs } \\
n=54\end{array}$ & $38.5(28.4), 32,7-150$ & & $12.4(10.2), 8,0-39$ & & $50.9(31.4), 45.5,14-169$ & \\
\hline $\begin{array}{l}56 \text { remaining RECs } \\
n=129\end{array}$ & $63.3(33.1), 55,10-188$ & $<0.0001$ & 18.9 (25.7), 11.5, 0-195 & NS & $81.9(38.6), 76,20-236$ & $<0.0001$ \\
\hline
\end{tabular}

protocols (of the 24 included in this study). Their approval times, as compared with those of the remaining RECs $(n=56)$ were shorter, with highly significant differences (table 6).

The time needed by the SMA for review and approval of MCT applications is shown in figure 2. In 16 out of 22 protocols $(73 \%)$ - for which the SMA did not demand additional information from the sponsor-the approval letter from the SMA was received at the sponsor's offices within 60 days from submission.

\section{DISCUSSION}

There are a number of reports from different European countries regarding the role of the REC in reviewing clinical trial protocols from different perspectives. ${ }^{35}$ 19-22 Following problems with the previous UK system, the NHS designed a new one by which one multicentre REC would review the protocol and the local RECs would limit their review to locality issues, with an aim to communicate the decision to the applicant within three weeks. ${ }^{11}{ }^{12}$ To improve timely and valuable MCT assessment in the UK, ${ }^{13}$ the Department of Health has recently issued two guidelines, ${ }^{26}{ }^{27}$ one of these ${ }^{27}$ being the UK's response to the EU directive. ${ }^{28}$ It should be highlighted that RECs are expected to work "efficiently to facilitate the good conduct of high quality research", and that "unjustified delay to such research is itself unethical". ${ }^{26}$ To this end, the guidelines included the Directive's requirements regarding the REC's decision for MCTs, that has to be communicated to the applicant within 60 calendar days (this time frame must include consideration of locality issues by local RECs). ${ }^{27}$ To ensure the fulfilment of this directive requirement, a similar approach to the British one has been proposed in Spain, although the review of the protocol by one REC and that of locality issues by the rest of the RECs involved should run in parallel. ${ }^{18}$

The sample of RECs involved in this study can be regarded as an accurate representation of all Spanish RECs: (a) these 62 RECs are located in those regions in which $97 \%$ of all clinical trials are performed, ${ }^{29}$ (b) those RECs located in the Madrid and Catalonia regions reviewed $60 \%$ of all applications included in this study, a figure close to the $55 \%$ of all trials conducted in our country, ${ }^{29}$ and (c) the six RECs which have reviewed most MCTs in Spain in $2000-01^{18}$ coincide with those in this study.

This study shows that the median time between submission and approval of a protocol was 48 days; however, the decision reached the sponsor's offices 10 days later (median) and the total median time needed from submission to reception of the approval was 62 days. These figures are very close to those observed in a study performed in the mid 1990s: 46 and 69 days (medians) for submission to approval, and for submission to reception, respectively, ${ }^{3}$ but far from those reported in the UK with a median (submission to reception) time between 28 and 42 days. ${ }^{2425}$ It can be

\begin{tabular}{|l|c|c|}
\hline & Sample & No with queries (\%) \\
\hline No of applications & 183 & $101(55)$ \\
\hline No of protocols & 24 & $24(100)$ \\
\hline No of RECs & 62 & $41(66)$ \\
\hline
\end{tabular}

Figure 1 Queries raised by research ethics committees (RECs) and course of events. *Answers approved by secretary or president without requiring an additional REC meeting.

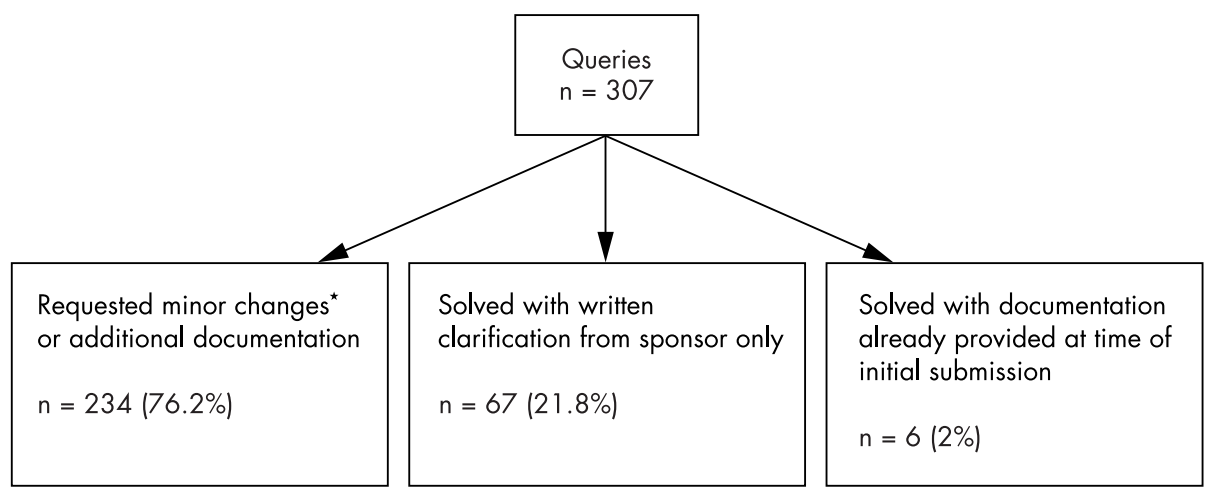



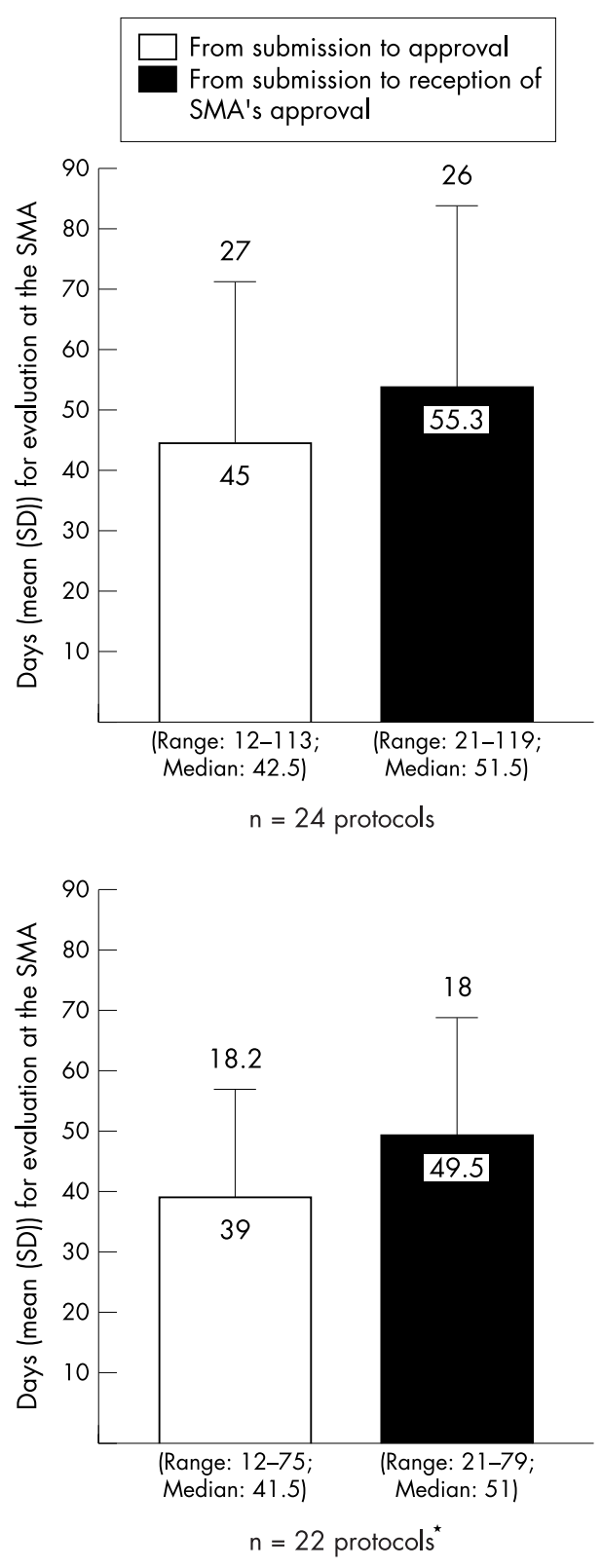

Figure 2 Timelines (days) for Spanish Medicine Agency (SMA) approval. "Excluding two trials which required submission of additional information requested by the SMA.

concluded that the efficiency of Spanish RECs has not changed since the mid 1990s. However, these results must be compared with caution. In this study, the majority of RECs (65\%) charged an evaluation fee for reviewing the MCT protocol, whereas in the previous one $e^{3}$ only $34 \%$ charged such a fee. This is relevant because this study shows that RECs requesting a fee are significantly more diligent in assessing and communicating their decision (60 days, median) than those evaluating protocols free of charge (81 days, median).

Even more important is the consideration of how queries raised by RECs affected the evaluation process. The results of this study showed that although the submission to approval time was significantly shorter (as expected) when no queries were raised (41 $v 55$ days, medians), this has little impact when submission to reception time is considered (61 v 69 days, medians). These figures are similar, again, to those observed in the previous study: ${ }^{3}$ in the mid 1990s 69 and
75 days (medians) were required from submission to reception of the approval letter from RECs, for protocols without and with queries raised, respectively. Most queries, as in the previous study ${ }^{3}$ were related to protocol related issues $(40 \%)$ and PIS wording $(38 \%)$, in contrast to the UK data, which show that PIS is the most common cause of queries. ${ }^{525}$ It is worth noting that $7 \%$ of all queries were related to the exact wording to be included in PIS regarding the Spanish personal data protection law, issued in 1999 following the EU Directive 95/46/EC. ${ }^{30}$

It should be highlighted that only half of the RECs that charged an evaluation fee or did not raise queries to the sponsor/investigator would comply with the 60 day time frame as required by the Directive. Among the most efficient are the six RECs that are leading the review of MCTs in our country. Each of these six RECs (all local, belonging to large university hospitals, five of them located in Madrid or Catalonia) reviewed in 2000 and 2001 around 200300 MCT protocols. ${ }^{18}$ In this study, they required 32 and 46 days (medians) for submission to approval and for submission to reception, respectively, being statistically significantly more efficient than the rest of RECs involved in this study.

These data suggest that there are serious organisational and/or administrative issues within most RECs (even within the top six RECs) that may explain why about 10 days (median) are needed to communicate their final decision. This is even more relevant if we take into consideration that most of them $(87 \%)$ used fax in their communications with the sponsor: it can be concluded that the RECs administrative staff require 1.5 weeks to prepare the approval letter. No improvement has been observed on the administrative issues in the last few years, since the same situation was observed in the previous study. ${ }^{3}$

Interestingly enough, phase III MCTs required statistically significantly shorter evaluation times than phase II and IV trials, although the number of queries were similar in these three types of trials. The reason behind this difference is that in this study queries raised by RECs on phase III MCTs were more commonly approved by the REC's secretary or president, not needing full REC meeting for their approval, than those queries raised for phase II or IV MCTs.

The results of this study are influenced by a critical event: a number of RECs (19; 31\%) only review a given (fixed) number of protocols per meeting. This means that a number of protocols were not reviewed in the first REC meeting after their submission, but had to wait for a second or even a third meeting later, which means a delay of one or more months. Therefore, for a fair assessment of RECs from the MCT protocol review and approval process point of view, an analysis can be made of what would have happened if all protocols had been reviewed in the first RECs' meetings. As the Directive ${ }^{16}$ states that the RECs would have "a maximum of 60 days from the date or receipt of a valid application to give its reasoned opinion to the applicant and the competent authority in the Member state", it is worthwhile assessing what would have happened if the time between submission and the date of review of the protocol would have been 15 days (median time requested by RECs to accept an application). In this case, and considering only those applications that raised no queries from RECs, most (70\%) of the approval letters would have arrived at the sponsors offices within the 60 day time frame; the median time of submission to reception would have been 36 days. This is relevant because the Ministry of Health is considering establishing a coordinating centre (it could be similar to COREC in the UK) that could be involved in deciding which REC should review the MCT protocol (ethical and scientific 
aspects) in depth, leaving the assessment-in parallel-of locality issues (for example, PIS, facilities) to the local RECs involved. If this is the option finally taken by the SMA, the decision, as in the UK model, ${ }^{31}$ should be left to the applicant as to which REC the protocol should be submitted, either to that suggested by the coordinating centre (that has available time in the next meeting), or to the one preferred by the applicant (which means that the protocol review must wait for available time in the preferred REC). Another approach, suggested by relevant members of 31 RECs in Spain is that the "single opinion" (ethical and scientific aspects of the protocol) should rely on the REC to whom the coordinating investigator of the MCT belongs, leaving the assessment of locality issues to the other RECs involved. ${ }^{18}$ The process decided by the Italian authorities as a response to the directive is in line with this approach: the REC of the coordinating investigator will issue the "single opinion" on the protocol in 30 days; the RECs of the other participating centres will have an additional 30 days to approve or reject the previously approved protocol. ${ }^{31}$

In any case, RECs in Spain should markedly improve their administrative functioning in order to be ready to comply with the EU Directive requirements. As has been suggested, ${ }^{3}{ }^{13}$ the use of electronic transmission for communicating REC decisions is critical to ensure an efficient process. But this can only be achieved if the letter is prepared in a very short period of time (for example, 48 hours) after the REC's meeting. It has been suggested ${ }^{18}$ that if the REC sends the approval letter to the sponsor (and/or investigator) by email and then mails it after signing it off, the process will save a considerable amount of time (no less than 10 days, as per the results of this study). This is relevant to ensure both the fulfilment of the directive requirements and the Spanish approval times vis a vis, for example, the UK, France (with only one REC involved), and Italy (from January 2004 onwards) in the start-up of MCT. To this end, and because RECs charging an evaluation fee are significantly more efficient, we suggest, as others have, ${ }^{18}$ that all RECs should charge a reasonable fee that should be used to improve their administrative and information technology resources in order to ensure timely communications with sponsors, investigators, and the competent authority (note that only 29\% of RECs currently use email in their communications). In 2004, when a single opinion for MCTs will be in place, the REC assessing the protocol should charge a fee that ensures both speed and quality in the protocol review process, an amount that could be close to what currently is charged by the multicentre RECs in the UK ( $£ 1000$, or $€ 1440)$ for industry sponsored trials; ${ }^{33}$ the fee for reviewing locality issues by other RECs involved, if this is the model finally adopted in Spain, should be considerably lower. Finally, all RECs willing to be considered as potential boards for review in MCTs should meet, at least on a monthly basis; otherwise it will be impossible for them to comply with the 60 day period required by the European regulation.

As stated in the Directive, ${ }^{16}$ the whole process of review and approval of an MCT includes the submission by the sponsor of "a valid request for authorisation to the competent authority of the Member State in which the sponsor plans to conduct the clinical trial". As mentioned above, in Spain currently the SMA must approve each trial before it can be initiated. The data from this study indicate that most (73\%) of the protocols' approvals are communicated to the sponsor within the 60 day period stated in the Directive. However, the fact that there is still a significant proportion of MCTs (27\%) for which the whole process by the SMA takes longer than this indicates that the procedure should be improved to ensure that the review and communication process can be completed within 60 days for all protocols.

\section{AUTHORS' NOTE}

The Directive 2001/20/EC came into force in May 2004, after this paper was accepted for publication. Almost all EC countries have adapted their regulations to comply with the provisions stated in this Directive.

\section{ACKNOWLEDGEMENTS}

We thank A Pedromingo for performing the statistical analysis.

\section{Authors' affiliations}

R Dal-Ré, R Ortega, E Morejón, Medical Department, GlaxoSmithKline,

Tres Cantos, Madrid, Spain

\section{REFERENCES}

1 Watling MIL, Dewhurst JK. Current experience of central versus local ethics approval in multicentre studies. J $R$ Coll Physicians Lond 1993;27:399-402.

2 Hotopf $M$, Wesseley S, Noah A. Are ethics committees reliable. J R Soc Med, 1995;88:31-3.

3 Dal-Re R, Espada J, Ortega R. Performance of research ethics committees in Spain. A prospective study of 100 applications for clinical trial protocols on medicines. J Med Ethics 1999;25:268-73.

4 Burman WJ, Reves RR, Cohn DL, et al. Breaking the camel's back: multicenter clinical trials and local institutional review boards. Ann Intern Med 2001;134:152-7.

5 Boyce M. Observational study of 353 applications to London multicentre research ethics committee 1997-2000. BMJ 2002;325:1081.

6 Mann H. Research ethics committees and public dissemination of clinical trial results. Lancet 2002;360:406-8.

7 Pich J, Carné X, Arnaiz JA, et al. Role of a research ethics committee in followup and publication of results. Lancet 2003;361:1015-16.

8 Office of Inspector General. Department of Health and Human Services. Institutional Review Boards: a time for reform, June 1998.OEl-01-97-00193.http://oig.hhs.gov/oei/reports//accessed 11 July 2002).

9 Lucena MI, Bosch F, Baños JE. Diez años de comités éticos de investigación clínica: los riesgos de la complacencia. Medicina Clinica (Barcelona) 2003;120:257-60.

10 Humphreys K, Trafton J, Wagner TH. The cost of Institutional Review Board procedures in multicenter observational research. Ann Intern Med 2003; 139:77.

11 NHS Executive. Ethics committee review of multicentre research. London: Department of Health, 1997, HSG (97), 23.

12 NHS Executive. Interim guidance: How should an LREC handle an MREC approved application? London: Department of Health, 1998.

13 Alberti KGMM. Multicentre research ethics committees: has the cure been worse than the disease. BMJ 2000;320:1157-8.

14 Real Decreto 561/1993, de 16 de abril, por el que se establecen los requisitos para la realización de ensayos clínicos con medicamentos. BOE 13 de mayo de, 1993.

15 Bianchi W, Furlani P, Alessi T, et al. Clinical trials: focus on Italy. Drug Inf J 2002;36:387-394.

16 Directive 2001/20/EC of the European parliament and the Council of 4 April 2001 on the approximation of the laws, regulations and administrative provisions of the Member States relating to the implementation of good clinical practice in the conduct of clinical trials on medicinal products for human use. Official Journal of the European Communities, 1 May 2001. L $121 / 34-44$.

17 Loi No 88-1138, 20 décembre 1988 relative à la protection des personnes qui se pretent à des recherches biomédicales. Journal Officiel de la République Française, 22 décembre 1988: 16032-5, Amendments:Loi No 90-86, 23 janvier 1990, Loi No 90-549, 2 juillet 1990, and Loi No 91-73, 18 juillet, 1991.

18 Avendaño C, Casas A, Dal-Re R, et al. Comités éticos de investigación clínica y "dictamen único" en los ensayos clínicos multicéntricos. Medicina Clínica (Barcelona) 2003;120:180-8.

19 Keinonen T, Nieminen S, Saareks V, et al. Acceptability and profile of the clinical drug trials underway in Finnish university hospitlas in the 1990s: Applications reviewed by Ethics Committees. Methods Find Exp Clin Pharmacol 2001;23:415-23.

20 Godfrey E, Wray E, Nicholson R. Another look at LREC annual reports. Bull Med Ethics 2001;171:13-21.

21 Maskell NA, Jones EL, Davies RJO. Variations in experience in obtaining local ethical approval for participation in a multi-centre study. $Q J$ Med 2003;96:305-7.

22 Huriet MC. Rapport d'information fait au nom de la commission des Affaires sociales sur le fonctionnement des comités consultatifs de protection des personnes dans la recherche biomédicale. Sénat, session ordinaire de 20002001, No 267.

23 Meade TW. The trouble with ethics committees. J R Coll Physicians Lond 1994;28:102-3.

24 Lux AL, Edwards SW, Osborne JP. Responses of local research ethics committees to a study with approval from multicentre research ethics committee. BMJ 2000;320:1182-3. 
25 Tully J, Ninis N, Boody R, et al. The new system of review of multicentre research ethics committees: a prospective study. $B M J$ 2000;320:1 179-82

26 Research Governance framework for Health and Social Care. Available at www.doh.gov.uk/research (accessed 2 August 2002).

27 Governance arrangements for NHS Research Ethics Committees. July 2001. Available at www.doh.gov.uk/research (accessed 2 August 2002)

28 Cave $\mathrm{E}$, Holm S. New governance arrangements for research ethics committees: is facilitating research achieved at the cost of participants' interest. J Med Ethics 2002;28:318-21.

29 Agencia Española del Medicamento. Informe de actividades 2001-2002 Ministerio de Sanidad y Consumo, 2003.
30 Directive 95/46/EC of the European Parliament and of the Council of 24 October 1995 on the protection of individuals with regard to the processing of personal data on the free movement of such data. Official Journal L 281, 23 November, 1995:31-50.

31 Central Office for Research Ethics Committees. Central allocation system for applications to MRECs. Available at www.corec.org.uk/centralallocations.htm (accessed 12 June 2003).

32 Attuazione della direttiva 2001/20/CE relativa all'applicazione della buona pratica clinica nell'esecuzione delle sperimentazione cliniche di medicinali per uso clinico. Decreto Legislativo 24 giugno 2003, n 211. Gazzetta Ufficiale della Repubblica Italiana n 184 del 9-8-2003, Suppl Ordinario n 130

33 Saunders J. Research ethics committees - time for change? Clin Med 2002;2:534-8. 